\title{
Agmatine protects Müller cells from high-concentration glucose-induced cell damage via N-methyl-D-aspartic acid receptor inhibition
}

\author{
NING HAN ${ }^{1}$, LI YU $^{1}$, ZHIDU SONG ${ }^{1}$, LIFU LUO $^{1}$ and YAZHEN WU ${ }^{2}$ \\ Departments of ${ }^{1}$ Ophthalmology and ${ }^{2}$ Ocular Fundus Disease, \\ The Second Hospital of Jilin University, Changchun, Jilin 130041, P.R. China
}

Received July 10, 2014; Accepted March 9, 2015

DOI: $10.3892 / \mathrm{mmr} .2015 .3540$

\begin{abstract}
Neural injury is associated with the development of diabetic retinopathy. Müller cells provide structural and metabolic support for retinal neurons. High glucose concentrations are known to induce Müller cell activity. Agmatine is an endogenous polyamine, which is enzymatically formed in the mammalian brain and has exhibited neuroprotective effects in a number of experimental models. The aims of the present study were to investigate whether agmatine protects Müller cells from glucose-induced damage and to explore the mechanisms underlying this process. Lactate dehydrogenase activity and tumor necrosis factor- $\alpha$ mRNA expression were significantly reduced in Müller cells exposed to a high glucose concentration, following agmatine treatment, compared with cells not treated with agmatine. In addition, agmatine treatment inhibited glucose-induced Müller cell apoptosis, which was associated with the regulation of $\mathrm{Bax}$ and $\mathrm{Bcl}-2$ expression. Agmatine treatment suppressed glucose-induced phosphorylation of mitogen-activated protein kinase (MAPK) protein in Müller cells. The present study demonstrated that the protective effects of agmatine on Müller cells were inhibited by $\mathrm{N}$-methyl-D-aspartic acid (NMDA). The results of the present study suggested that agmatine treatment protects Müller cells from high-concentration glucose-induced cell damage. The underlying mechanisms may relate to the anti-inflammatory and antiapoptotic effects of agmatine, as well as to the inhibition of the MAPK pathway, via NMDA receptor suppression. Agmatine may be of use in the development of novel therapeutic approaches for patients with diabetic retinopathy.
\end{abstract}

Correspondence to: Dr Yazhen Wu, Department of Ocular Fundus Disease, The Second Hospital of Jilin University, 4026 Yatai Avenue, Changchun, Jilin 130041, P.R. China

E-mail: yazhenwu@hotmail.com

Key words: agmatine, N-methyl-D-aspartic acid receptor, Müller cell, diabetic retinopathy, mitogen-activated protein kinase

\section{Introduction}

Diabetic retinopathy (DR) is one of the common complications associated with diabetic mellitus (DM) and it is the leading cause of blindness in people over the age of 50 (1). Recent research has demonstrated that DR is not only a microvascular disease but may be a result of neurodegenerative processes. Glucose-induced neuron and glial cell damage may occur in the absence of microvascular injury (2). Müller cells, the principal glial cells of the retina, provide neurons with adenosine triphosphate and nutrition (3), control levels of $\mathrm{K}^{+}, \mathrm{H}^{+}$and neurotransmitters in extracellular space (4), and are involved in signal transmission by communicate with retinal neurons through corresponding receptors and transporters (5). Müller cells are the only cells in the retina that contain glutamine synthetase (GS). This enzyme is associated with the transformation of glutamate into glutamine via synaptic pathways $(6,7)$. In healthy retinas, Müller cells are essential for the removal of glutamate and help to prevent the accumulation of a toxic concentration in the retina (8). In patients with DM, Müller cells are not able to transform glutamate to glutamine and, therefore, glutamate concentrations are elevated in the retinas of these individuals (9). Studies have shown that glial fibrillary acidic protein expression is upregulated and that the nucleus changes in Müller cells, during the early stages of DR (3,10-14). In addition, Müller cells secrete a number of growth factors, cytokines (15) and inflammatory regulators (16) during the development of DR, and are an important source of inflammatory factors. Therefore, the development of strategies to protect Müller cells would be beneficial in the treatment of DR.

Agmatine is an endogenous polyamine, which is formed by enzymatic decarboxylation of L-arginine in the mammalian brain $(17,18)$. Agmatine is a neurotransmitter and neuromodulator, which is secreted from specific neuron networks $(19,20)$. It interacts with a number of ligand-gated ion channels and binds with certain cellular receptors (21). Importantly, it is capable of inhibiting $\mathrm{N}$-methyl-D-aspartic acid receptors (NMDARs) in a voltageand concentration-dependent manner $(22,23)$. Furthermore, agmatine inhibits nitric oxide synthase (NOS) isoforms by suppressing catalytic activity (24). Previous studies have 
suggested that agmatine may protect retinal ganglion cells from oxidative stress $(25,26)$, promote glial cell survival in spinal cord injury (27) and attenuate LPS-induced microglial damage (28). However, the majority of studies have focused on the protective effects of agmatine via NMDAR inhibition in the neurons, or via NOS inhibition in the glial cells of the central nervous system (CNS). To the best of our knowledge, there have been no reports of the effects of agmatine treatment on damaged glial cells in patients with DR. NMDAR, an ionotropic glutamate receptor that mediates $\mathrm{Ca}^{2+}$ entry when it is activated, is present in the Müller cells of vertebrate retinas (29). Based on the data described above, agmatine is suggested to exert beneficial effects in DR damaged glial cells via NMDAR inhibition. In the present study, the protective effects of agmatine on high-concentration glucose-induced Müller cell injury were evaluated in vitro. The association between the protective effects of agmatine, and the expression of NMDARs and downstream signaling proteins in Müller cells was also investigated.

\section{Materials and methods}

Cell culture. A total of 30 male Sprague-Dawley rats, aged 4 weeks, obtained from Jilin University Laboratory Center (Jilin, China) were used for the primary Müller cells culture. The experimental protocols were approved by the ethics committee of Jilin University (Jilin, China).

Isolated retinas were washed twice using phosphate-buffered saline (PBS) and then separated using a Pasteur pipette (Xuansheng, Shanghai, China) in Dulbecco's modified Eagle's medium (DMEM; Gibco Life Technologies, Carlsbad, CA, USA). Cells were filtered using a cell strainer (Nanjing Union Bio-Technology, Nanjing, China), and then seeded and maintained using DMEM medium, containing $10 \%$ fetal bovine serum (Gibco Life Technologies). Cells were cultured at $37^{\circ} \mathrm{C}$ in humidified $5 \% \mathrm{CO}_{2}$, and the medium was replaced every 2 days. Subsequent to 5 days of isolation, the cells were passaged every 3 days.

In order to conduct the cell survival assay, cells from the third passage were seeded into 96 -well plates and divided into seven groups: (1) Healthy glucose control group (control; $25 \mathrm{mM}$ glucose and $30 \mathrm{mM}$ mannitol); (2) high-concentration glucose group (HG; 55 mM glucose); (3) high-concentration glucose, low-concentration agmatine treatment group (HAL; $55 \mathrm{mM}$ glucose and $50 \mu \mathrm{M}$ agmatine); (4) high-concentration glucose, medium-concentration agmatine treatment group (HAM; $55 \mathrm{mM}$ glucose and $100 \mu \mathrm{M}$ agmatine); (5) high-concentration glucose, high-concentration agmatine treatment group (HAH; $55 \mathrm{mM}$ glucose and $200 \mu \mathrm{M}$ agmatine); (6) high-concentration glucose, agmatine treatment and NMDA group (HAN; $55 \mathrm{mM}$ glucose, $100 \mu \mathrm{M}$ agmatine and $100 \mu \mathrm{M}$ NMDA); and (7) high-concentration glucose and NMDA group (HN; $55 \mathrm{mM}$ glucose and $100 \mu \mathrm{M}$ NMDA). Subsequently, cells of passage three were seeded in to 6-well or 96-well plates and divided into four groups, as the medium concentration of agmatine was considered optimal: (1) Control; (2) HG; (3) HAM; and (4) HAN.

Prior to receiving treatments, cells in each group were starved for $12 \mathrm{~h}$ and exposed to DMEM, containing the corresponding treatments for $48 \mathrm{~h}$.
Table I. Oligonucleotide primers for RT-PCR.

\begin{tabular}{ll}
\hline Primer & \multicolumn{1}{c}{ Sequence (5'-3') } \\
\hline TNF- $\alpha-F$ & TGGCGTGTTCATCCGTTCT \\
TNF- $\alpha-R$ & CCACTACTTCAGCGTCTCGT \\
$\beta$-actin-F & GGAGATTACTGCCCTGGCTCCTAGC \\
$\beta$-actin-R & GGCCGGACTCATCGTACTCCTGCTT
\end{tabular}

TNF- $\alpha$, tumor necrosis factor- $\alpha$; RT-PCR, reverse transcription-polymerase chain reaction; $\mathrm{F}$, forward; $\mathrm{R}$, reverse.

Immunofluorescence. Müller cells were fixed on coverslips using 4\% paraformaldehyde (Sinopharm Chemical Reagent Co., Ltd., Beijing, China) for $15 \mathrm{~min}$, followed by washing in PBS for $5 \mathrm{~min}$. Coverslips were then treated with $0.1 \%$ TritonX-100 (Sigma-Aldrich, St. Louis, MO, USA) for $30 \mathrm{~min}$, at room temperature. Following a wash stage in PBS for $5 \mathrm{~min}$, blocking was achieved using goat serum (Solarbio Science \& Technology, Co., Ltd. Beijing, China) for $15 \mathrm{~min}$ at room temperature. Cells were then incubated overnight with the polyclonal NMDAR1 (1:100 dilution, catalogue no. orb99445; Biorbyt Ltd., Cambridge, UK) or GS antibodies (1:50 dilution; catalogue no. sc-9067; Santa Cruz Biotechnology, Inc., Dallas, TX, USA), at $4^{\circ} \mathrm{C}$. Coverslips were washed using PBS and incubated with fluorescein isothiocyanate (FITC)-conjugated goat anti-rabbit secondary antibody (1:100; catalogue no. A0562; Beyotime Institute of Biotechnology, Haimen, China) for $1 \mathrm{~h}$, at room temperature. Following a wash phase using PBS, slips were then stained with DAPI (Biosharp, Heifei, China) for $5 \mathrm{~min}$. Fluorescence images were captured using a fluorescence microscope (FV1000S-SIM/IX81, Olympus Corporation, Tokyo, Japan).

Cell survival assay. In order to conduct a cell survival assay, $10 \mu$ Cell Counting kit-8 solution (Beyotime Institute of Biotechnology) was added into each well of the plate, and plates were incubated at $37^{\circ} \mathrm{C}$ for $1 \mathrm{~h}$. The plates were then analyzed using an enzyme-linked immunosorbent assay (ELISA) reader (ELX-800, BioTek Instruments, Inc., Winooski, VT, USA), at $450 \mathrm{~nm}$.

Lactate dehydrogenase $(\mathrm{LDH})$ measurements. In order to conduct LDH activity measurements, supernatants from the Müller cells were centrifuged at $1,100 \mathrm{x} \mathrm{g}$ for $5 \mathrm{~min}$. LDH activity was measured using a standard LDH kit (Nanjing Jiancheng Bioengineering Institute, Nanjing, China). Results were calculated using the following formula according to the assay kit used: LDH activity $(\mathrm{U} / \mathrm{L})=$ optical density $(\mathrm{OD})$ value (sample-control)/OD value (standard-blank) x standard concentration $(2 \mathrm{mmol} / \mathrm{l}) \times 1,000$.

RNA extraction and reverse transcription-polymerase chain reaction $(R T-P C R)$ analysis. Cells were collected and washed with PBS. Total RNA was extracted using RNA simple total RNA kit (Tiangen Biotech Co., Ltd., Beijing, China) according to the manufacturer's instructions. cDNA was synthesized with oligonucleotide primers, using super Moloney Murine 
Leukemia Virus Reverse Transcriptase (BioTeke Corporation, Beijing, China). RT-PCR was performed with $1 \mu \mathrm{g}$ cDNA using the $2 \mathrm{x}$ Power Taq PCR Master Mix (BioTeke Corporation) and SYBR Green (Solarbio Science \& Technology, Co., Ltd.). PCR reactions were performed using a PCR system (Exicycler 96, Bioneer Corporation, Daejeon, Korea). Relative mRNA levels were normalized against $\beta$-actin and presented as $2^{-\Delta \Delta C t}$. Primers used are listed in Table I.

TNF- $\alpha$ expression analysis using ELISA. Following treatment for $48 \mathrm{~h}$, the medium was centrifuged at $1,100 \times \mathrm{g}$ for $5 \mathrm{~min}$ and supernatants were collected in order to conduct a TNF- $\alpha$ assay. TNF- $\alpha$ expression levels were quantified according to the manufacturer's instructions using a Rat TNF- $\alpha$ ELISA kit specific to rats (Multisciences, Hangzhou, China).

Flow cytometric determination of apoptosis. Double staining using propidium iodide (PI) was performed in order to analyze annexin V-FITC binding to membrane phosphatidylserine and cellular DNA, according to the manufacturer's instructions (Nanjing KeyGen Biotech. Co., Ltd., Nanjing, China). Following treatment for $48 \mathrm{~h}$, cells were harvested and centrifuged at $88 \mathrm{x} \mathrm{g}$ for $10 \mathrm{~min}$, washed twice with PBS, and resuspended in $500 \mu 1$ binding buffer (Nanjing KeyGen Biotech. Co., Ltd.). Annexin V-FITC (5 $\mu \mathrm{l})$ and $5 \mu \mathrm{l}$ PI were then added, and the samples were incubated for $15 \mathrm{~min}$ in darkness at room temperature. Samples were acquired immediately on a BD FACS Calibur flow cytometer (BD Biosciences, San Jose, CA, USA) using CellQuest software, version 3.0 (BD Biosciences). Annexin V-FITC and PI emissions were detected in the FL 1 and FL 2 channels. For each analysis, 100,000 counts were recorded. Data analysis was performed using FCS Express V3.00 (DeNovo Software, Thornhill, ON, Canada). In each plot, the lower left quadrant represented viable cells; the upper left quadrant, necrotic cells; the lower right quadrant, early apoptotic cells; and the upper right quadrant, late apoptotic cells.

Hoechst staining. Apoptotic or necrotic cell death was characterized by staining cells using Hoechst 33342 . Cells were washed twice with PBS and fixed with $5 \mathrm{ml}$ fixing solution for $5 \mathrm{~min}$. Subsequently, cells were stained with $10 \mu \mathrm{g} / \mathrm{ml}$ Hoechst 33342 (Beyotime Institute of Biotechnology) for 5 min at $37^{\circ} \mathrm{C}$ in darkness. Cells were then washed twice with PBS and imaged using a digital camera attached to a fluorescence microscope (AE31, Motic China Group Co., Ltd., Xiamen, China).

Western blot analysis. Cells were harvested and lysed by incubating with an NP-40 lysis buffer (Beyotime Institute of Biotechnology) containing $1 \%$ phenylmethanesulfonylfluoride on ice, for $5 \mathrm{~min}$. The cells were centrifuged at $10,010 \mathrm{x}$ g for $10 \mathrm{~min}$ at $4^{\circ} \mathrm{C}$ and protein concentrations were determined using a commercial bicinchoninic acid protein assay kit (Beyotime Institute of Biotechnology). Heat-induced denaturation was conducted in a loading buffer [31\% SDS (w/v), $0.67 \%$ bromophenol blue (w/v) and 33.3\% glycerol (v/v)] and western blot analysis was performed, using $40 \mu \mathrm{g}$ of protein from each cell lysate. Samples and standards were loaded on an SDS gel and separated at $80 \mathrm{~V}$ for $2.5 \mathrm{~h}$. Proteins were then transferred to polyvinylidene fluoride membranes $(0.45 \mu \mathrm{m}$; EMD Millipore, Billerica, MA, USA) in a transfer buffer [0.3\% Tris (w/v), $1.44 \%$ glycine $(\mathrm{w} / \mathrm{v})$ and $20 \%$ methanol $(\mathrm{v} / \mathrm{v})]$ at $70 \mathrm{~V}$ for $1.5 \mathrm{~h}$. Following electroblotting, membranes were washed with Tris-Buffered saline with Tween $20^{\circledR}$ (TBST; Sinopharm Chemical Reagent Co., Ltd.) and blocked with TBST containing 5\% non-fat milk at room temperature, for $1 \mathrm{~h}$. Subsequently, the membranes were incubated in TBST containing 5\% non-fat milk and primary antibodies over night, at $4^{\circ} \mathrm{C}$. The following polyclonal primary antibodies were used: Bcl-2 (1:500; BA0412) and Bax (1:1,000; BA0315) (Boster Biological Technology, Wuhan, China); c-caspase-3 (cleaved-caspase-3; 1:1,000; bs-0081R; Beijing Biosynthesis Biotechnology, Beijing, China), p-ERK (AM071) and ERK (AM076) (1:1,000; Beyotime Institute of Biotechnology, Beijing, China); p-JNK (WLP006) and JNK (WLN006) (1:1,000, Wanlei Life Sciences, Shenyang, China); and p-p38 (sc-101758) and p38 (sc-7149) (1:100 and 1:200, respectively; Santa Cruz Biotechnology, Santa Cruz, CA, USA). Membranes were washed in TBST four times and incubated for $45 \mathrm{~min}$ at $37^{\circ} \mathrm{C}$ with horseradish peroxidase-linked secondary antibodies (1:5,000; Beyotime Institute of Biotechnology). Subsequently, the membranes were washed in TBST five times, incubated for $1 \mathrm{~min}$ in enhanced chemiluminescence solution (7 Sea Pharmtech, Shanghai, China) and then exposed to a Fuji Rx 100 X-ray film (Fuji Photo Film, Tokyo, Japan). The membranes were then incubated in stripping buffer (Beyotime Institute of Biotechnology) for $15 \mathrm{~min}$ at room temperature, followed by incubation and detection of the reference gene, $\beta$-actin with a polyclonal $\beta$-actin antibody (WL0001; Wanlei Life Sciences). The density of the protein bands was normalized to the $\beta$-actin signal.

Statistical analysis. Data are expressed as the mean \pm standard deviation. Multiple comparisons were analyzed using one-way analysis of variance followed by Bonferroni's test using SPSS software, version 19 (IBM SPSS, Armonk, NY, USA). P<0.05 was considered to indicate a statistically significant difference.

\section{Results}

Müller cells express GS and NMDAR. In the retina, GS is only expressed in Müller cells. Therefore, GS was used as an indicator of the presence of Müller cells. To confirm the success of cell isolation and NMDAR expression in the cells, isolated Müller cells were immunostained using GS or NMDAR antibodies, and costained using DAPI. The nuclei were positive for DAPI (Fig. 1A, C, D and F) and the cytoplasm exhibited GS (Fig. 1B and C) or NMDAR (Fig. 1E and F) positive staining.

Agmatine improves Müller cell survival rate. As shown in Fig. 2, Müller cell survival was lower in cells in the HG group compared with those in the control group $(50.77 \pm 3.28 \%$, compared with $100 \pm 3.56 \%, \mathrm{P}<0.01)$. The survival rate of Müller cells was significantly higher in cells in the HAM group compared with those in the HG group $(85.98 \pm 10.46 \%$, $\mathrm{P}<0.01)$. Although the mean cell survival rate value was lower, no significant difference was observed between the HAM and control groups. High-concentration agmatine treatment (HAH; $200 \mu \mathrm{M}$ ) did not lead to an increase in cell survival 

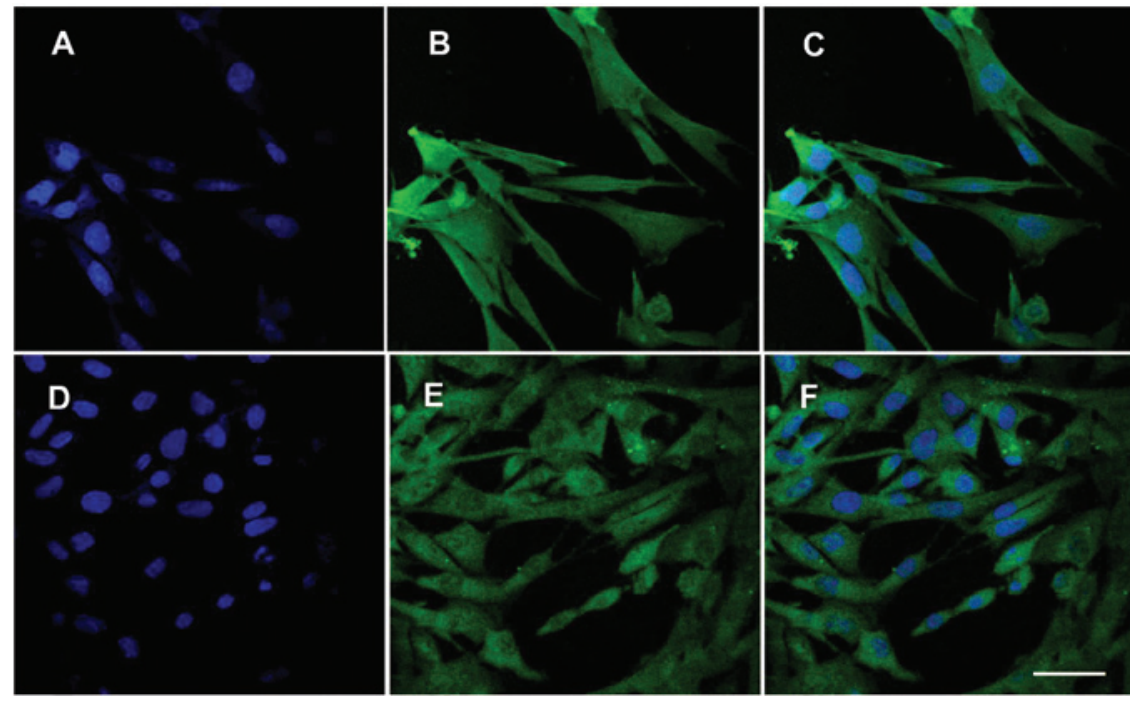

Figure 1. Expression of GS and NMDAR1 in Müller cells. (A) DAPI staining; (B) GS expression in Müller cells; (C) merged; (D) DAPI staining; (E) NMDAR expression in Müller cells; (F) merged. Scale bar $=40 \mu \mathrm{m}$. NMDAR, N-methyl-D-aspartic acid receptor; GS. glutamine synthetase; DAPI, 4',6-diamidino-2-phenylindole; NMDAR, N-methyl-D-aspartic acid receptor.

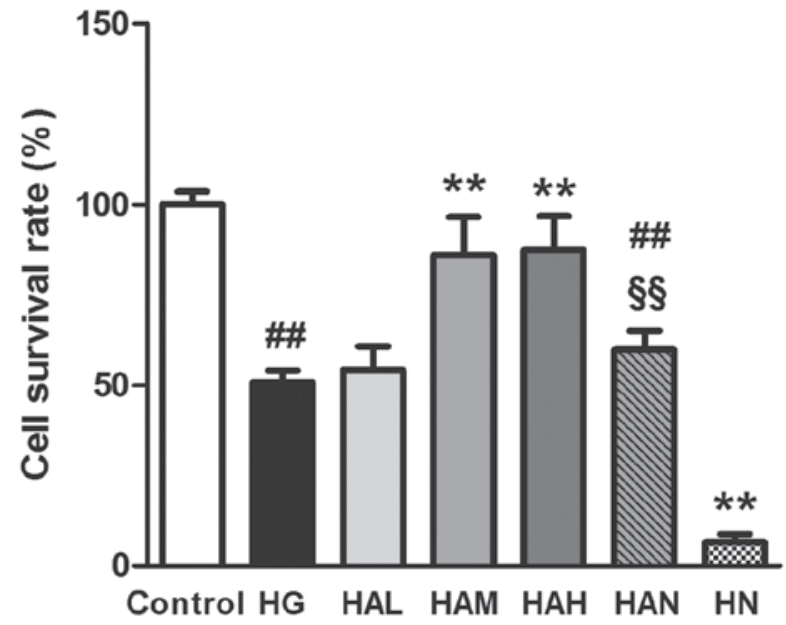

Figure 2. Effect of agmatine on survival rate of glucose-damaged Müller cells. Glucose treatment led to lower cell survival rates in Müller cells compared with those treated with agmatine (100 and $200 \mu \mathrm{M})$. NMDA caused a reversal in the protective effects of agmatine treatment. Data are presented as the mean \pm standard deviation $(n=3) .{ }^{\# \prime} \mathrm{P}<0.01$ compared with the control group,${ }^{* *} \mathrm{P}<0.01$ compared with the $\mathrm{HG}$ group and ${ }^{*} \mathrm{P}<0.01$ compared with the HAM group. NMDA, N-methyl-D-aspartic acid; HAM, high-concentration glucose, medium agmatine concentration treatment; $\mathrm{HG}$, high glucose.

rate compared with cells in the HAM group (100 $\mu \mathrm{M}$ agmatine treatment). Following treatment with NMDA and agmatine (100 $\mu \mathrm{M}$; HAN group), the cell survival was significantly lower compared with cells in the HAM group $(59.84 \pm 5.22 \%$, $\mathrm{P}<0.01)$. High glucose plus NMDA treatment without agmatine (HN group) led to a significant reduction in the survival rate of Müller cells $(6.52 \pm 2.20 \%)$.

Agmatine inhibits high-concentration glucose-induced LDH activity in Müller cells. LDH activity was measured in order to investigate cell viability. As shown in Fig. 3, Müller cell exposure to high glucose concentrations (HG group) led to an increase in LDH activity compared with the control

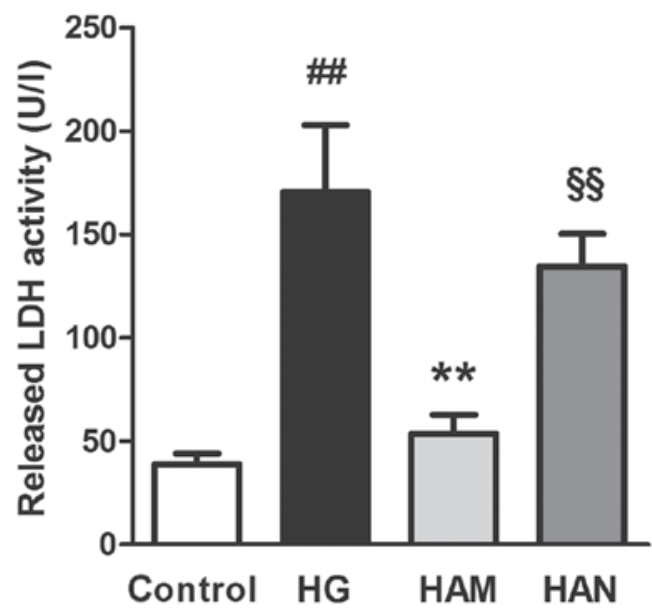

Figure 3. Effect of agmatine on glucose-induced LDH activity in Müller cells. Agmatine treatment led to lower LDH activity in Müller cells and NMDA treatment reversed this effect. Data are presented as the mean \pm standard deviation $(\mathrm{n}=3)$. ${ }^{\# /} \mathrm{P}<0.01$ compared with the control group, ${ }^{* *} \mathrm{P}<0.01$ compared with the HG group and ${ }^{*} \mathrm{P}<0.01$ compared with the HAM group. LDH, lactate dehydrogenase; NMDA, N-methyl-D-aspartic acid; HAM, high glucose, medium agmatine concentration treatment; HG, high glucose.

group $(\mathrm{P}<0.01)$, indicating a cellular toxic effect. LDH activity was significantly lower in Müller cells in the HAM group compared with those in the HG group $(\mathrm{P}<0.01)$. No significant difference was observed between the LDH activity levels of cells in the HAM group compared with those in the control group. LDH activity was significantly higher in cells in the HAN group compared with those in the HAM group.

Agmatine inhibits high-concentration glucose-induced $T N F-\alpha$ release and $m R N A$ expression. TNF- $\alpha$ is a primary inflammatory factor that is released during the early stages of inflammation and is an indicator of glial cell activity. Previous studies have reported that Müller cells release TNF- $\alpha$ during the development of DR (30). In order to determine whether TNF- $\alpha$ 

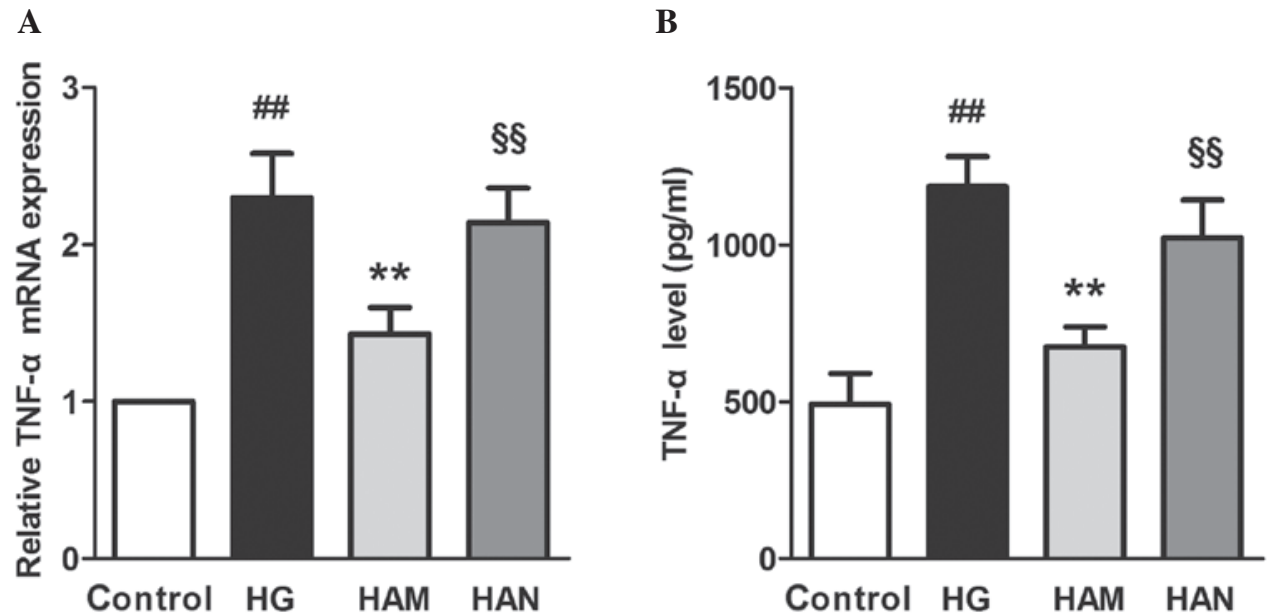

Figure 4. Effect of agmatine on HG-induced TNF- $\alpha$ inflammatory factor release. HG-induced TNF- $\alpha$ mRNA expression (A) and protein expression (B) in Müller cells. Agmatine treatment decreased TNF- $\alpha$ mRNA and protein expression levels in the culture medium, while NMDA reversed the effect of agmatine. Data are presented as the mean \pm standard deviation $(n=3) .{ }^{\# \#} \mathrm{P}<0.01$ compared with the control group, ${ }^{* *} \mathrm{P}<0.01$ compared with the HG group and ${ }^{\text {"}} \mathrm{P}<0.01$ compared with the HAM group. TNF- $\alpha$, tumor necrosis factor- $\alpha$; HG, high glucose; HAM, middle concentration of agmatine treatment; NMDA, N-methyl-D-aspartic acid.

A

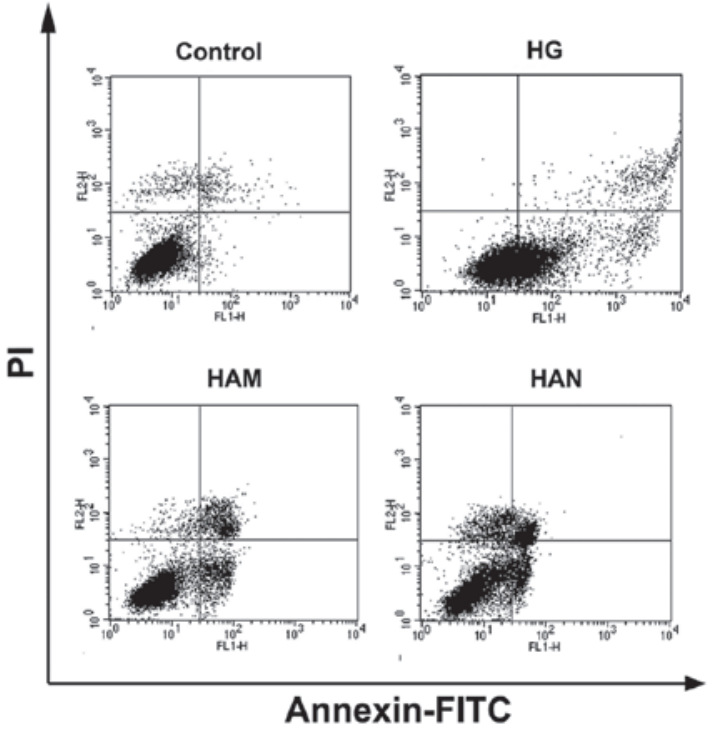

B

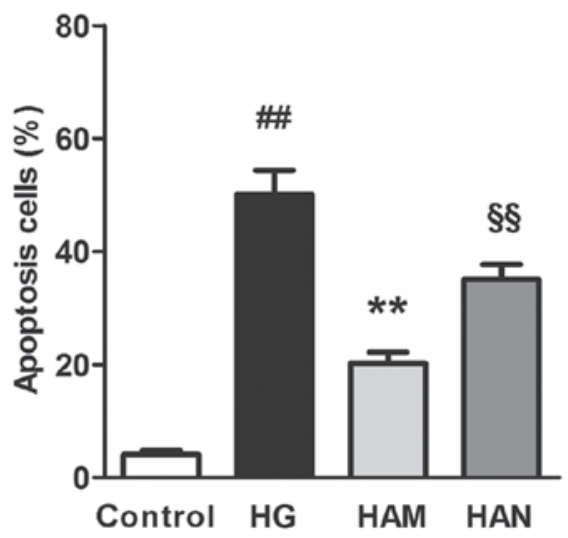

Figure 5. Effect of agmatine on glucose-induced apoptosis in Müller cells. (A) Flow cytometric analysis demonstrated apoptotic cells. (B) Histogram of cell apoptotic percentage. Data are presented as the mean \pm standard deviation $(\mathrm{n}=3),{ }^{\# \#} \mathrm{P}<0.01$ compared with the control group, ${ }^{* *} \mathrm{P}<0.01$ compared with the HG group and "P<0.01 compared with the HAM group. HG, high glucose; HAM, high glucose, medium agmatine concentration treatment; NMDA, N-methyl-D-aspartic acid; HAH, high glucose, high agmatine concentration treatment group; PI, propidium iodide; FITC, fluorescein isothiocyanate.

production may be regulated by agmatine treatment, TNF- $\alpha$ mRNA expression and levels of TNF- $\alpha$ were assayed. Fig. 4 shows that TNF- $\alpha$ mRNA expression and TNF- $\alpha$ release into the medium were significantly higher in cells in the HG group compared with those in the control group $(\mathrm{P}<0.01)$. Agmatine treatment (HAM; $100 \mu \mathrm{M}$ agmatine) led to a significant reduction in TNF- $\alpha$ levels in the medium and TNF- $\alpha$ mRNA expression levels, compared with cells in the HG group $(\mathrm{P}<0.01)$. NMDA treatment (HAN group) led to significantly higher TNF- $\alpha$ levels in the medium and TNF- $\alpha$ mRNA expression levels, compared with cells in the HAM group.

Agmatine inhibits high-concentration glucose-induced cell apoptosis in Müller cells. A small number of cells
$(4.10 \pm 0.71 \%)$ were positive for Annexin V-FITC and PI staining in the control group. Following exposure to $55 \mathrm{mM}$ glucose for $48 \mathrm{~h}$, the percentage of apoptotic significantly increased in the HG group compared with the control group (50.07 $\pm 4.30 \%$; $\mathrm{P}<0.01$; Fig. 5B). The number of apoptotic cells in the HAM group was significantly lower compared with the HG group $(20.19 \pm 1.98 \% ; \mathrm{P}<0.01)$. The number of apoptotic cells was significantly higher in the HAN group compared with the HAM group $(35.10 \pm 2.57 \%$; $\mathrm{P}<0.01)$, suggesting that NMDA treatment suppressed the effects of agmatine on the Müller cells.

Following cell apoptosis, nuclear condensation and DNA fragmentation was detected using Hoechst 33342 staining and fluorescence microscopy. As illustrated in Fig. 6, following 

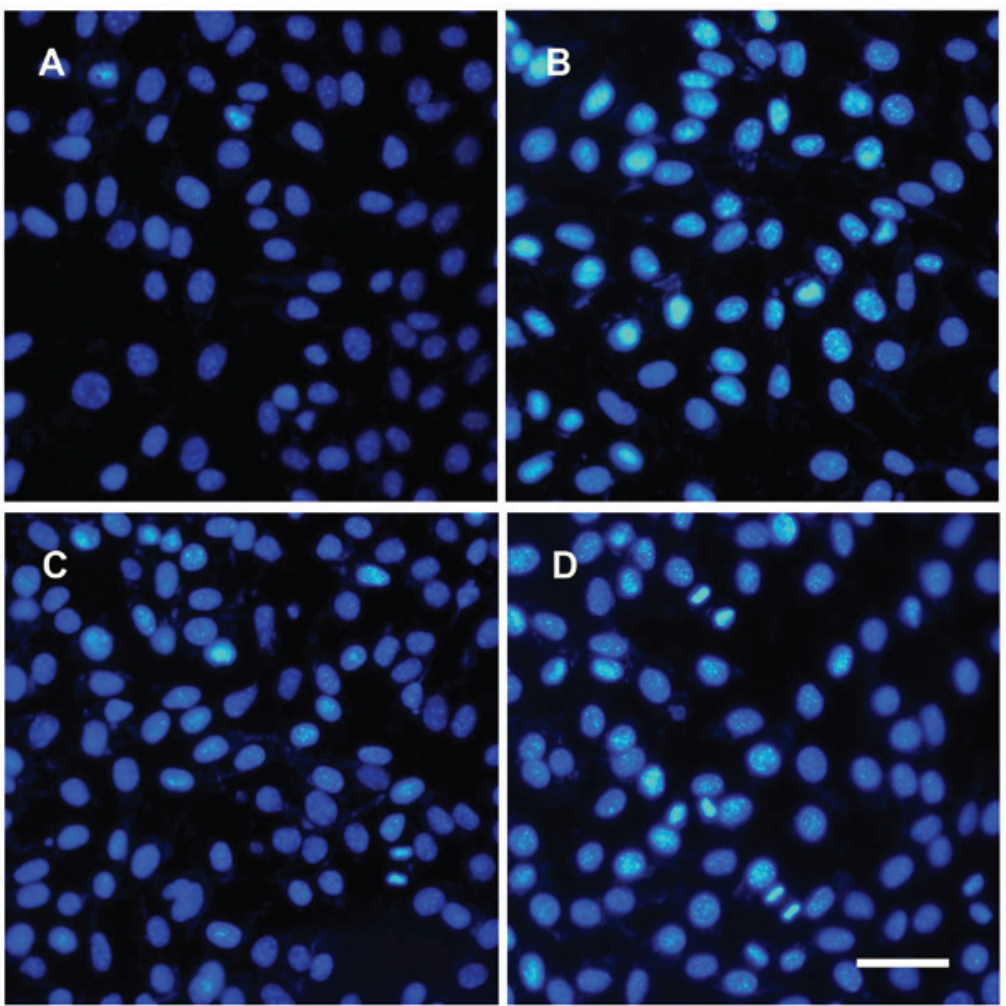

Figure 6. Hoechst 33342 staining in Müller cells. Agmatine treatment reduced glucose-induced cell apoptosis in Müller cells and NMDA reversed this effect. (A) Healthy control; (B) high glucose; (C) high glucose with agmatine; (D) high glucose with agmatine and NMDA. Scale bar=50 $\mu$ m. NMDA, N-methyl-D-aspartic acid.

incubation with glucose for $48 \mathrm{~h}$, a number of Müller cells with condensed and fragmented nuclei were observed (Fig. 6B). Agmatine treatment (HAM group) led to a marked decrease in the number of apoptotic cells (Fig. 6C) and cells in the HAN group demonstrated nuclear condensation and DNA fragmentation following NMDA treatment. Therefore NMDA appeared to suppress the antiapoptotic effect of agmatine (Fig. 6D).

Agmatine inhibits high-concentration glucose-induced apoptosis via regulation of apoptotic signaling protein expression. In order to further investigate the molecular mechanisms underlying the protective effects of agmatine on glucose-induced apoptosis, the expression of apoptosis-associated proteins Bax, Bcl-2 and cleaved-caspase 3 were investigated.

The results of the present study demonstrated that glucose treatment led to a decrease in $\mathrm{Bcl}-2$ expression and an increase in Bax expression levels in Müller cells, compared with those in the control group (Fig. 7). Bcl-2 expression levels were higher and Bax expression levels were lower in the HAM group compared those the HG group. In addition, caspase-3 expression, which is an important effector of the apoptotic pathway, was higher in cells in the HG group compared with that in the control group $(\mathrm{P}<0.01)$. A significant decrease in caspase-3 expression was observed in cells in the HAM group compared with that in cells in the $\mathrm{HG}$ group $(\mathrm{P}<0.01)$. NMDA treatment reversed the effects of agmatine on $\mathrm{BCl}-2$, Bax and caspase-3 expression in glucose-damaged Müller cells.

Agmatine inhibits glucose-induced mitogen-activated protein kinase (MAPK) activity. MAPKs are downstream proteins that are associated with the NMDAR signaling pathway. Phosphorylation levels of three MAPK-associated proteins, extracellular signal regulated kinase (ERK), c-Jun N-terminal kinase (JNK) and p38 kinase (p38), were detected in the present study. As shown in Fig. 8, ERK, JNK and p38 protein phosphorylation levels were significantly higher in cells in the HG group compared with those in the control group $(\mathrm{P}<0.01)$. Following agmatine treatment (100 $\mu \mathrm{M}$; HAM group), ERK, JNK and p38 phosphorylation levels were significantly decreased compared with the HG group $(\mathrm{P}<0.01)$. No marked changes in ERK, JNK or p38 total protein expression levels were observed (data not shown).

\section{Discussion}

Agmatine is associated with the CNS, it interacts with certain receptors and neuronal pathways, and it demonstrates neuroprotective effects. It has been investigated for use in the treatment of CNS-associated disorders, such as spinal cord damage, ischemia, traumatic brain injury and depression (31). Agmatine has been shown to block NMDA currents in rat hippocampal neurons (23). Therefore, the effect of agmatine may be mediated via NMDA receptor inhibition (32). The protective effects of agmatine against cell damage are not restricted to the CNS; effects have also been observed in retinal ganglion cells (26,33-35). The results of the present study suggested that agmatine treatment may protect Müller cells from glucose-induced cell damage.

In the present study, glucose treatment was used to mimic DR in Müller cells. Glucose treatment induced cell death in 
$\mathbf{A}$

Bcl-2

$\beta$-actin

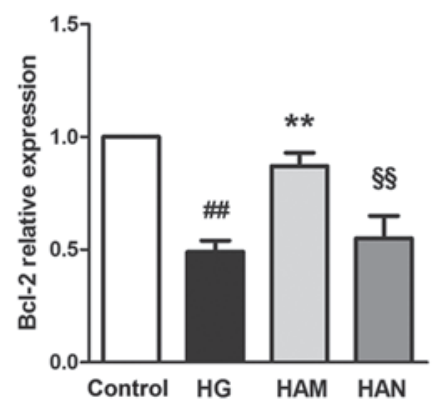

B

\section{Bax}

$\beta$-actin
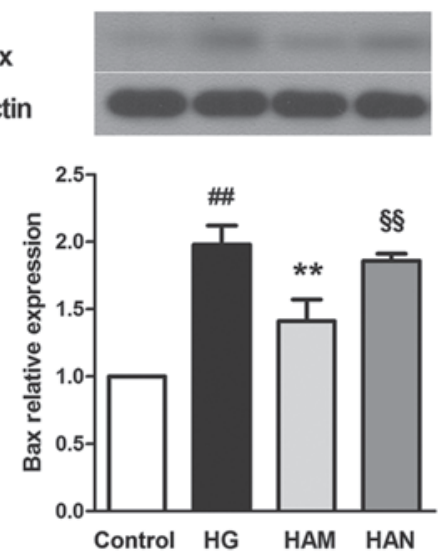

C
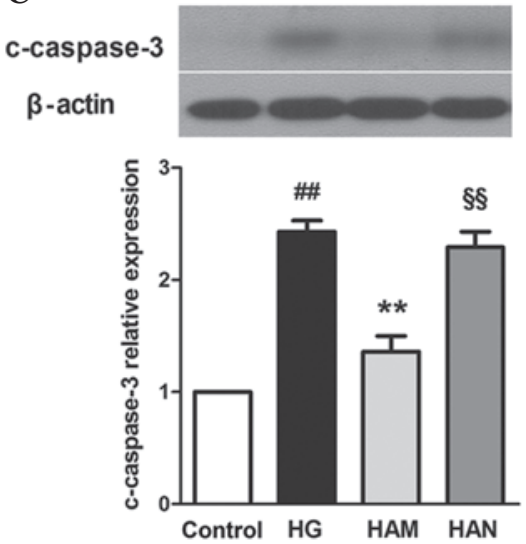

Figure 7. Agmatine treatment may protect cells from glucose-induced apoptosis by increasing Bcl-2 (A), and decreasing Bax (B) and c-caspase-3 (C) expression levels. NMDA reversed the effects of agmatine. Data are presented as the mean \pm standard deviation $(\mathrm{n}=3)$. ${ }^{\#} \mathrm{P}<0.01$ compared with the control group, ${ }^{* *} \mathrm{P}<0.01$ compared with the HG group and ${ }^{\#} \mathrm{P}<0.01$ compared with the HAM group. HG, high glucose; NMDA, N-methyl-D-aspartic acid; c-caspase-3, cleaved-caspase-3; HAM, middle concentration of agmatine treatment.

A
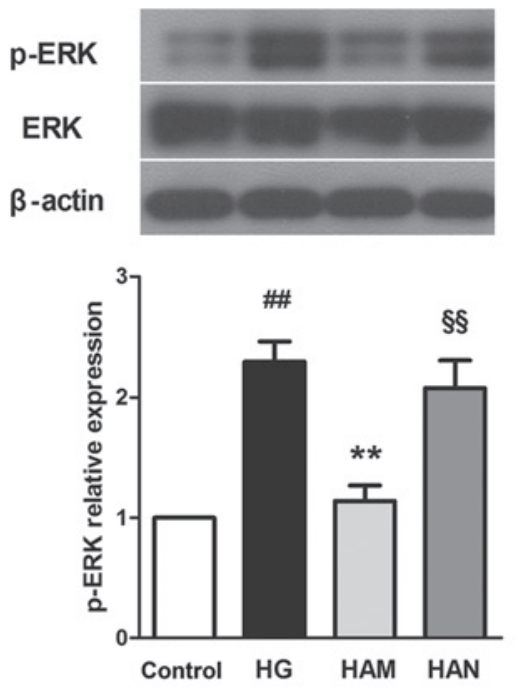

B p-JNK
JNK
$\beta$-actin

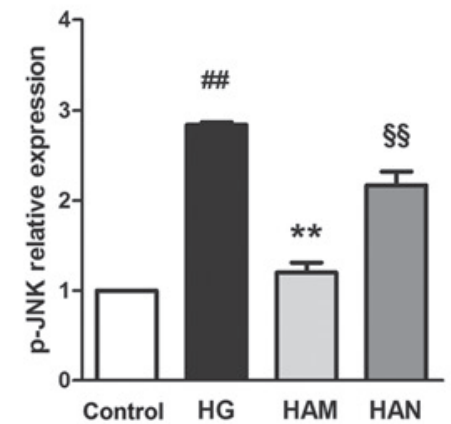

C
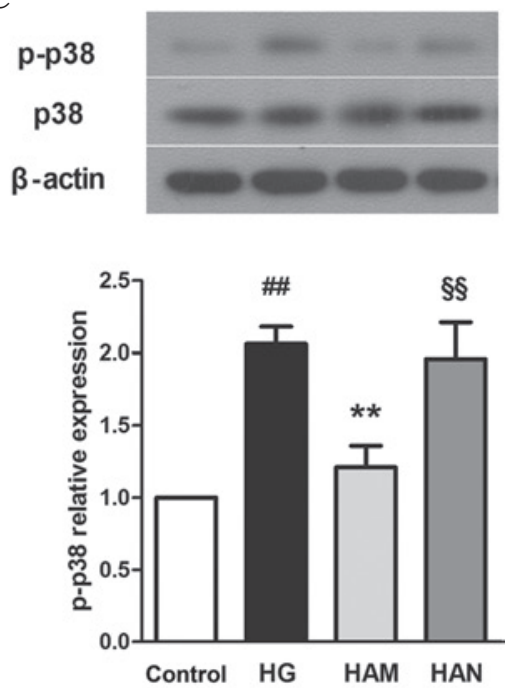

Figure 8. Effects of agmatine on glucose-induced MAPK signaling. Agmatine treatment may protect cells from glucose-induced cell stress by reducing ERK (A), JNK (B) and p38 (C) phosphorylation. NMDA blocked the effects of agmatine. Data are presented as the mean \pm standard deviation $(\mathrm{n}=3)$, ${ }^{\# \#} \mathrm{P}<0.01$ compared with the control group, ${ }^{* *} \mathrm{P}<0.01$ compared with the HG group and ${ }^{\text {" }} \mathrm{P}<0.01$ compared with the HAM group. p-, phospho; c-caspase-3, cleaved-caspase-3; ERK, extracellular signal regulated kinase; JNK, c-Jun N-terminal kinase; p38, p38 kinase; HG, high glucose; HAM, middle concentration of agmatine treatment; NMDA, N-methyl-D-aspartic acid; MAPK, mitogen-activated protein kinase.

Müller cells, and this observation was reversed following treatment with 100 and $200 \mu \mathrm{M}$ agmatine. In the present study, $100 \mu \mathrm{M}$ agmatine treatment reduced LDH activity in Müller cells in the HAM group, compared with those in the HG group. NMDA treatment reversed the protective effects of agmatine. It is possible that agmatine treatment may inhibit NMDAR, which may contribute to the protective effects of agmatine in glucose-damaged Müller cells. However, clarification of these processes requires further research.

Similar to astrocytes in the brain, Müller cells release proinflammatory cytokines in response to inflammatory responses. TNF- $\alpha$ is a marker of inflammation and is released during the early stages of inflammation. The results of the present study demonstrated that TNF- $\alpha$ expression was higher in Müller cells in the HG group compared with the control group, reflecting Müller cell inflammation. Agmatine treatment of cells in the HAM group led to a decrease in TNF- $\alpha$ release from Müller cells and TNF- $\alpha$ mRNA expression. These results were reversed following NMDA treatment. These observations are in accordance with previous studies, which showed that NMDAR treatment leads to increased TNF- $\alpha$ mRNA expression and secretion in cells $(36,37)$. The results of the present study suggest that agmatine may reduce glucose-induced inflammation in Müller cells via NMDAR inhibition.

Retinal ganglion cells undergo cell apoptosis in patients with DR (38). The present study demonstrated that Müller cells undergo apoptosis in response to glucose treatment. In the present study, according to flow cytometric analysis and Hoechst staining, glucose treatment led to increased levels of Müller cell apoptosis compared with control cells. Agmatine treatment demonstrated antiapoptotic effects in glucose-damaged Müller cells. In order to investigate the 
mechanisms underlying the antiapoptotic effect of agmatine, signaling protein expression levels were analyzed. The Bcl-2 family consists of a group of important proteins that are involved in cell apoptosis regulation. Bcl-2 is associated with tumor development $(39,40)$; specifically, Bcl-2 expression inhibits the morphological changes during cell apoptosis, including plasma membrane blebbing, DNA cleavage and nuclear condensation, and negatively regulates cell death (41). By contrast, Bax is a proapoptotic member of the family. A number of apoptotic signals may activate Bax expression, followed by the formation of homo-oligomers and the permeabilization of the outer mitochondrial membrane, leading to the release of mitochondrial intermembrane contents into the cytosol (42). Bcl-2 may interact with Bax and inhibit its oligomerization, thereby inhibiting apoptosis (43). In general, the ratio of Bcl-2 to Bax proteins determines the level of cell apoptosis. Caspase-3 may be activated via extrinsic and intrinsic apoptotic pathways. Following activation by caspase-8, caspase-3 may cleave with multiple substrates within the cell, which induces cell apoptosis (44). The present study demonstrated that high-concentration glucose treatment led to a decrease in Bcl-2 expression and an increase in Bax expression, compared with control cells. Agmatine treatment promoted the upregulation of Bcl-2 and suppressed the expression of Bax, thereby contributing to a reduction in c-caspase-3 expression in cells in the HAM group. The results of the present study are consistent with a previous study that demonstrated that agmatine treatment is capable of suppressing the expression of apoptotic proteins in rat retinal ganglion cells (34). The results, therefore, suggested that $\mathrm{Bcl}-2$ protein regulation may be associated with the antiapoptotic effects of agmatine.

MAPKs consist of a family of protein kinases that control a number of physiological processes and respond to various stresses signals. Three kinases, ERK, JNK and p38, are considered to be associated with stress-induced cell death. The present study demonstrated that ERK, JNK and p38 expression levels were induced in cells in the GS group, according to western blot analysis. Therefore, MAPKs may be associated with high-concentration glucose-induced Müller cell damage. In addition, MAPKs have been shown to be activated by NMDA-induced $\mathrm{Ca}^{2+}$ influx $(45,46)$, and they contribute to NMDA-induced neurotoxicity in rat retinas (47). A previous study has shown that NMDAR1 expression was higher in mouse glomerular endothelial cells, following glucose treatment, compared with control cells in vitro (48). In the present study, increased phosphorylation of MAPKs proteins was observed in cells in the HG group compared with those in the control group. Agmatine treatment of cells in the HAM group reduced ERK, JNK and p38 phosphorylation levels, compared with cells in the HG group. ERK, JNK and p38 phosphorylation levels in cells in the HAN group were significantly lower than those in the HAM group. Therefore, glucose may induce NMDAR expression in Müller cells, which may activate MAPK protein expression. Agmatine treatment reduced the phosphorylation levels of MAPKs by inhibiting NMDAR. Therefore, the inhibition of MAPKs may partly contribute to the protective effects of agmatine in Müller cells.

In the present study, agmatine treatment was shown to increase cell survival rate, decrease LDH activity, reduce TNF- $\alpha$ expression, regulate apoptotic-associated Bcl-2 and
Bax protein expression, and inhibit ERK, JNK and p38 protein phosphorylation, in glucose-damaged Müller cells. Therefore, agmatine may protect Müller cells from glucose-induced cell death via anti-inflammatory, antiapoptotic and MAPK signaling inactivation effects. Furthermore, protective effects of agmatine were reversed following NMDA treatment, which indicates that agmatine protection of the Müller cells may be associated with NMDAR inhibition. However, the present study did not investigate whether the effects of agmatine are associated with pathways independent of NMDAR. Furthermore, the mechanisms underlying the effects observed in the present study require further investigation. In conclusion, agmatine may be an effective for treatment in DR and is a novel therapeutic candidate for this disease.

\section{References}

1. Congdon N, O'Colmain B, Klaver CC, Klein R, Muñoz B, Friedman DS, Kempen J, Taylor HR and Mitchell P; Eye Diseases Prevalence Research Group: Causes and prevalence of visual impairment among adults in the United States. Arch Ophthalmol 122: 477-485, 2004.

2. Lieth E, Gardner TW, Barber AJ and Antonetti DA; Penn State Retina Research Group: Retinal neurodegeneration: Early pathology in diabetes. Clin Experiment Ophthalmol 28: 3-8, 2000.

3. Schellini SA, Gregório EA, Spadella CT, Machado JL and de-Moraes-Silva MA: Müller cells and diabetic retinopathy. Braz J Med Biol Res 28: 977-980, 1995.

4. Newman E and Reichenbach A: The Müller cell: A functional element of the retina. Trends Neurosci 19: 307-312, 1996.

5. Du JL, Xu LY and Yang XL: Glycine receptors and transporters on bullfrog retinal Müller cells. Neuroreport 13: 1653-1656, 2002.

6. Lewis GP, Erickson PA, Kaska DD and Fisher SK: An immunocytochemical comparison of Müller cells and astrocytes in the cat retina. Exp Eye Res 47: 839-853, 1988.

7. Linser P and Moscona AA: Induction of glutamine synthetase in embryonic neural retina: Localization in Müller fibers and dependence on cell interactions. Proc Natl Acad Sci USA 76: 6476-6480, 1979.

8. Li Q and Puro DG: Diabetes-induced dysfunction of the glutamate transporter in retinal Müller cells. Invest Ophthalmol Vis Sci 43: 3109-3116, 2002.

9. Kowluru RA, Engerman RL, Case GL and Kern TS: Retinal glutamate in diabetes and effect of antioxidants. Neurochem Int 38: 385-390, 2001.

10. Lieth E, Barber AJ, Xu B, Dice C, Ratz MJ, Tanase D and Strother JM: Glial reactivity and impaired glutamate metabolism in short-term experimental diabetic retinopathy. Penn State Retina Research Group. Diabetes 47: 815-820, 1998.

11. Barber AJ, Antonetti DA and Gardner TW: Altered expression of retinal occludin and glial fibrillary acidic protein in experimental diabetes. The Penn State Retina Research Group. Invest Ophthalmol Vis Sci 41: 3561-3568, 2000.

12. Rungger-Brändle E, Dosso AA and Leuenberger PM: Glial reactivity, an early feature of diabetic retinopathy. Invest Ophthalmol Vis Sci 41: 1971-1980, 2000.

13. Li Q, Zemel E, Miller B and Perlman I: Early retinal damage in experimental diabetes: Electroretinographical and morphological observations. Exp Eye Res 74: 615-625, 2002.

14. Curtis TM, Hamilton R, Yong PH, McVicar CM, Berner A, Pringle R, Uchida K, Nagai R, Brockbank S and Stitt AW: Müller glial dysfunction during diabetic retinopathy in rats is linked to accumulation of advanced glycation end-products and advanced lipoxidation end-products. Diabetologia 54: 690-698, 2011.

15. Zhong Y, Li J, Chen Y, Wang JJ, Ratan R and Zhang SX: Activation of endoplasmic reticulum stress by hyperglycemia is essential for Müller cell-derived inflammatory cytokine production in diabetes. Diabetes 61: 492-504, 2012.

16. Walker RJ and Steinle JJ: Role of beta-adrenergic receptors in inflammatory marker expression in Müller cells. Invest Ophthalmol Vis Sci 48: 5276-5281, 2007.

17. Tabor CW and Tabor H: Polyamines. Annu Rev Biochem 53: 749-790, 1984. 
18. Li G, Regunathan S, Barrow CJ, Eshraghi J, Cooper R and Reis DJ: Agmatine: An endogenous clonidine-displacing substance in the brain. Science 263: 966-969, 1994.

19. Otake K, Ruggiero DA, Regunathan S, Wang H, Milner TA and Reis DJ: Regional localization of agmatine in the rat brain: An immunocytochemical study. Brain Res 787: 1-14, 1998.

20. Reis DJ, Yang XC and Milner TA: Agmatine containing axon terminals in rat hippocampus form synapses on pyramidal cells. Neurosci Lett 250: 185-188, 1998.

21. Raasch W, Schäfer U, Chun J and Dominiak P: Biological significance of agmatine, an endogenous ligand at imidazoline binding sites. Br J Pharmacol 133: 755-780, 2001.

22. Piletz JE, Chikkala DN and Ernsberger P: Comparison of the properties of agmatine and endogenous clonidine-displacing substance at imidazoline and alpha-2 adrenergic receptors. J Pharmacol Exp Ther 272: 581-587, 1995.

23. Yang XC and Reis DJ: Agmatine selectively blocks the $\mathrm{N}$-methyl-D-aspartate subclass of glutamate receptor channels in rat hippocampal neurons. J Pharmacol Exp Ther 288: 544-549, 1999.

24. Satriano J, Kelly CJ and Blantz RC: An emerging role for agmatine. Kidney Int 56: 1252-1253, 1999.

25. Iizuka Y, Hong S, Kim CY, Kim SK and Seong GJ: Agmatine pretreatment protects retinal ganglion cells (RGC-5 cell line) from oxidative stress in vitro. Bio cell 32: 245-250, 2008

26. Iizuka Y, Hong S, Kim CY, Yang WI, Lee JE and Seong GJ: Protective mechanism of agmatine pretreatment on RGC-5 cells injured by oxidative stress. Braz J Med Biol Res 43: 356-358, 2010.

27. Park YM, Lee WT, Bokara KK, Seo SK, Park SH, Kim JH Yenari MA, Park KA and Lee JE: The multifaceted effects of agmatine on functional recovery after spinal cord injury through Modulations of BMP-2/4/7 expressions in neurons and glial cells. PLoS One 8: e53911, 2013

28. Ahn SK, Hong S, Park YM, Choi JY, Lee WT, Park KA and Lee JE: Protective effects of agmatine on lipopolysaccharide-injured microglia and inducible nitric oxide synthase activity. Life Sci 91: 1345-1350, 2012.

29. Uchihori Y and Puro DG: Glutamate as a neuron-to-glial signal for mitogenesis: Role of glial N-methyl-D-aspartate receptors. Brain Res 613: 212-220, 1993.

30. Mysona BA, Al-Gayyar MM, Matragoon S, Abdelsaid MA El-Azab MF, Saragovi HU and El-Remessy AB: Modulation of p75(NTR) prevents diabetes- and proNGF-induced retinal inflammation and blood-retina barrier breakdown in mice and rats. Diabetologia 56: 2329-2339, 2013.

31. Piletz JE, Aricioglu F, Cheng JT, Fairbanks CA, Gilad VH, Haenisch B, Halaris A, Hong S, Lee JE, Li J, et al: Agmatine: Clinical applications after 100 years in translation. Drug Discov Today 18: 880-893, 2013.

32. Olmos G, DeGregorio-Rocasolano N, Paz Regalado M, Gasull T, Assumpció Boronat M, Trullas R, Villarroel A, Lerma J and García-Sevilla JA: Protection by imidazol(ine) drugs and agmatine of glutamate-induced neurotoxicity in cultured cerebellar granule cells through blockade of NMDA receptor. Br J Pharmacol 127: 1317-1326, 1999.

33. Hong S,Kim CY,Lee JEand Seong GJ: Agmatine protects cultured retinal ganglion cells from tumor necrosis factor-alpha-induced apoptosis. Life Sci 84: 28-32, 2009.
34. Hong S, Lee JE, Kim CY and Seong GJ: Agmatine protects retinal ganglion cells from hypoxia-induced apoptosis in transformed rat retinal ganglion cell line. BMC Neurosci 8: 81, 2007.

35. Zhu MY, Wang WP and Bissette G: Neuroprotective effects of agmatine against cell damage caused by glucocorticoids in cultured rat hippocampal neurons. Neuroscience 141: 2019-2027, 2006.

36. Kawabata H, Setoguchi T, Yone K, Souda M, Yoshida H, Kawahara K, Maruyama I and Komiya S: High mobility group box 1 is upregulated after spinal cord injury and is associated with neuronal cell apoptosis. Spine (Phila Pa 1976) 35: 1109-1115, 2010.

37. McNearney TA, Ma Y, Chen Y, Taglialatela G, Yin H, Zhang R and Westlund KN: A peripheral neuroimmune link: Glutamate agonists upregulate NMDA NR1 receptor mRNA and protein, vimentin, TNF-alpha, and RANTES in cultured human synoviocytes. Am J Physiol Regul Integr Comp Physiol 298: R584-R598, 2010.

38. Kern TS and Barber AJ: Retinal ganglion cells in diabetes. J Physiol 586: 4401-4408, 2008.

39. Hanahan D and Weinberg RA: The hallmarks of cancer. Cell 100: 57-70, 2000.

40. Vaux DL, Cory S and Adams JM: Bcl-2 gene promotes haemopoietic cell survival and cooperates with c-myc to immortalize pre-B cells. Nature 335: 440-442, 1988.

41. Ola MS, Nawaz M and Ahsan $\mathrm{H}$ : Role of Bcl-2 family proteins and caspases in the regulation of apoptosis. Mol Cell Biochem 351: 41-58, 2011.

42. Wei MC, Zong WX, Cheng EH, Lindsten T, Panoutsakopoulou V, Ross AJ, Roth KA, MacGregor GR, Thompson CB and Korsmeyer SJ: Proapoptotic BAX and BAK: A requisite gateway to mitochondrial dysfunction and death. Science 292: 727-730, 2001.

43. Youle RJ and Strasser A: The BCL-2 protein family: Opposing activities that mediate cell death. Nat Rev Mol Cell Biol 9: 47-59, 2008.

44. Ghavami S, Hashemi M, Ande SR, Yeganeh B, Xiao W, Eshraghi M, Bus CJ, Kadkhoda K, Wiechec E, Halayko AJ and Los M: Apoptosis and cancer: Mutations within caspase genes. J Med Genet 46: 497-510, 2009.

45. Ko HW, Park KY, Kim H, Han PL, Kim YU, Gwag BJ and Choi EJ: $\mathrm{Ca}^{2+}$-mediated activation of $\mathrm{c}$-Jun $\mathrm{N}$-terminal kinase and nuclear factor kappa B by NMDA in cortical cell cultures. J Neurochem 71: 1390-1395, 1998.

46. Nicole O, Ali C, Docagne F, Plawinski L, MacKenzie ET, Vivien D and Buisson A: Neuroprotection mediated by glial cell line-derived neurotrophic factor: Involvement of a reduction of NMDA-induced calcium influx by the mitogen-activated protein kinase pathway. J Neurosci 21: 3024-3033, 2001.

47. Munemasa Y, Ohtani-Kaneko R, Kitaoka Y, Kuribayashi K, Isenoumi K, Kogo J, Yamashita K, Kumai T, Kobayashi S, Hirata $\mathrm{K}$ and Ueno S: Contribution of mitogen-activated protein kinases to NMDA-induced neurotoxicity in the rat retina. Brain Res 1044: 227-240, 2005.

48. Kundu S, Pushpakumar SB, Tyagi A, Coley D and Sen U: Hydrogen sulfide deficiency and diabetic renal remodeling: Role of matrix metalloproteinase-9. Am J Physiol Endocrinol Metab 304: E1365-E1378, 2013. 